\title{
Emission properties of Zinc Gallate nanophosphors
}

\author{
Mun Keun LEE ${ }^{1}$ and Shinhoo KANG ${ }^{1, \dagger}$ \\ ${ }^{1}$ Department of Materials Science and Engineering, Seoul National University, \\ 1 Gwanak-ro, Gwanak-gu, Seoul 08826, Republic of Korea
}

\begin{abstract}
Nano-sized $\mathrm{ZnGa}_{2} \mathrm{O}_{4}, \mathrm{ZnGa}_{2} \mathrm{O}_{4}: \mathrm{Cr}$ and $\mathrm{ZnGa}_{2} \mathrm{O}_{4}$ :Ti phosphors were synthesized by low-temperature combustion method and the luminescent properties were studied in comparison with those from conventional solid-state reaction. The combustion reaction resulted in a single-phase spinel structure and the particles were 5-10 $\mathbf{~ m m}$ in size. Of all samples, undoped nano $\mathrm{ZnGa}_{2} \mathrm{O}_{4}$ exhibited an intrinsic blue emission and Ti-doped nano $\mathrm{ZnGa}_{2} \mathrm{O}_{4}$ had a tendency of white emission whereas $\mathrm{Cr}$-doped nano $\mathrm{ZnGa}_{2} \mathrm{O}_{4}$ showed red emissions. Titanium ions in spinel structure was found to exist as in $\mathrm{Ti}^{3+}$ and $\mathrm{Ti}^{4+}$, but favouring trivalent state. The oxidation state of $\mathrm{Cr}$ ions was confirmed as $3^{+}$in nano $\mathrm{ZnGa}_{2} \mathrm{O}_{4}$.

(C2018 The Ceramic Society of Japan. All rights reserved.
\end{abstract}

Key-words : $\mathrm{ZnGa}_{2} \mathrm{O}_{4}$, Nano spinel, Phosphor, Photoluminescence, Combustion

[Received September 30, 2017; Accepted March 5, 2018]

\section{Introduction}

$\mathrm{ZnGa}_{2} \mathrm{O}_{4}$ is a semiconducting material that crystallizes in a normal spinel $\mathrm{AB}_{2} \mathrm{O}_{4}$ structure (cubic spinel, $\mathrm{Fd}-3 \mathrm{~m}$ ) with an optical band gap of $4.4 \mathrm{eV} .{ }^{1), 2)}$ The A site $\left(\mathrm{Zn}^{2+}\right)$ ions occupy tetrahedral sites with full $T_{d}$ symmetry, and the B site $\left(\mathrm{Ga}^{3+}\right)$ ions are in octahedral sites with six-fold distorted octahedral coordination and $\mathrm{D}_{3 \mathrm{~d}}$ point group. The trigonal axis of the B sites is coincident with the (111) axis and the site has a centre of inversion (No. 277 in the International Tables for Crystallography Volume A). ${ }^{3)}$

$\mathrm{ZnGa}_{2} \mathrm{O}_{4}$ has recently gained attention due to its potential as a phosphor host material with prospective uses such as an Ultraviolet (UV) and low-voltage emitter for application in diverse fields, field emission displays, thin-film electroluminescent devices, and vacuum fluorescent displays. ${ }^{4), 5)}$ The recent development not only in advanced biological imaging technologies has further recognized the potential of $\mathrm{ZnGa}_{2} \mathrm{O}_{4},{ }^{6)-8)}$ but also in the field of photocatalytic activities for water splitting and air purification. ${ }^{9)-12)}$ The oxide-based spinel structure of $\mathrm{ZnGa}_{2} \mathrm{O}_{4}$ provides advantageous physical and chemical properties as a phosphor since it is more stable under a high electric field and strong electron bombardment than conventional sulphide-based phosphors. ${ }^{4)}$

In general, UV or low-voltage electron excitation causes $\mathrm{ZnGa}_{2} \mathrm{O}_{4}$ to emit a strong blue emission owing to a transition via the self-activation centre at the $\mathrm{Ga}-\mathrm{O}$ groups. ${ }^{5), 13)}$ $\mathrm{ZnGa}_{2} \mathrm{O}_{4}$ acts as an excellent host for multicolour-emitting materials that shift its emission wavelength to different regions of visible spectrum. ${ }^{14)}$ For example, doping with a

Corresponding author: S. Kang; E-mail: shinkang@snu. ac.kr transitional metal or rare-earth element, such as chromium or europium, shifts the emission from blue to red, ${ }^{15)-18)}$ whereas manganese or terbium cause green emission. ${ }^{19), 20)}$

Other applications, such as white lighting, employ a yellow-emitting phosphor like $\mathrm{YAG}: \mathrm{Ce}^{3+}$ together with InGaN blue LED chips. ${ }^{21)}$ However, low colour rendering is the major drawback of such a system, arising from the lack of red emissions and different degradation rates of chip and phosphor. Therefore, the development of a singlecomposition white-emitting phosphor for UV or near-UV excitations has been suggested to improve the colour rendering and stability. ${ }^{22)}$ However, such white emissions are rarely reported. 23 )

Most oxide phosphors, including $\mathrm{ZnGa}_{2} \mathrm{O}_{4}$, have generally been synthesized by a conventional solid-state reaction ${ }^{4)}$ at high temperatures (above $1000^{\circ} \mathrm{C}$ ). For $\mathrm{ZnGa}_{2} \mathrm{O}_{4}$, high-temperature processing often causes volatilization of $\mathrm{ZnO}$ with severe agglomeration and grain growth. ${ }^{5)}$ This prohibits the production of ultrafine and non-agglomerated nanopowders with narrow size distribution, which could be an essential characteristics of useful phosphors. ${ }^{24)} \mathrm{A}$ spherical shape and clean surface are also important for phosphor particles to minimize the scattering of light and to maximize their packing density. ${ }^{25)}$ Therefore, wet chemistry, such as sol-gel, ${ }^{26)}$ hydrothermal, ${ }^{27)}$ use of polymeric precursor (Pechini), ${ }^{28)}$ co-precipitation ${ }^{29)}$ and combustion $^{30)}$ method, has been suggested as an alternative for the development of nano-sized phosphors.

This study reports the synthesis of nano-sized $\mathrm{ZnGa}_{2} \mathrm{O}_{4}$ spinel phosphors. Undoped, $\mathrm{Cr}^{3+}$-doped, and $\mathrm{Ti}^{3+}$-doped samples were made via a simple combustion method at temperatures lower than the conventional method. The phosphors were characterized in terms of size, photoluminescence and emission mechanism, using X-ray 
diffraction (XRD), high-resolution transmission electron microscopy (HR-TEM), photoluminescence emission (PLE) spectroscopy, and X-ray photoelectron spectroscopy (XPS).

\section{Eperimental section}

\subsection{Materials}

Zinc(II) nitrate hexahydrate $\left[\mathrm{Zn}\left(\mathrm{NO}_{3}\right)_{2} \cdot 6 \mathrm{H}_{2} \mathrm{O}\right]$ (purity $98 \%$ ), gallium(III) nitrate hydrate $\left[\mathrm{Ga}\left(\mathrm{NO}_{3}\right)_{3} \cdot x \mathrm{H}_{2} \mathrm{O}\right]$ (purity $99.9 \%$ ), chromium(III) nitrate nonahydrate $\left[\mathrm{Cr}\left(\mathrm{NO}_{3}\right)_{3}\right.$. $9 \mathrm{H}_{2} \mathrm{O}$ ] (purity 99\%), titanium(IV) oxyacetylacetonate $\left\{\mathrm{TiO}\left[\mathrm{CH}_{3} \mathrm{COCH}=\mathrm{C}(\mathrm{O}-) \mathrm{CH}_{3}\right]_{2}\right\}$ (purity 90\%) and urea $\left[\mathrm{CO}\left(\mathrm{NH}_{2}\right)_{2}\right]$ (purity 99\%) were purchased from SigmaAldrich and used without further purification.

\subsection{Synthesis}

All reagents were purchased and used without further purification. Zinc nitrate hexahydrate $\left[\mathrm{Zn}\left(\mathrm{NO}_{3}\right)_{2} \cdot 6 \mathrm{H}_{2} \mathrm{O}\right.$, Sigma-Aldrich, Reagent grade, 98\%], gallium nitrate hydrate $\left[\mathrm{Ga}\left(\mathrm{NO}_{3}\right)_{3} \cdot x \mathrm{H}_{2} \mathrm{O}\right.$, Sigma-Aldrich, $98 \%$ trace metals basis], urea $\left(\mathrm{NH}_{2} \mathrm{CONH}_{2}\right.$, Sigma-Aldrich, ACS reagent, 99.0-100.5\%), chromium nitrate nonahydrate $\left[\mathrm{Cr}\left(\mathrm{NO}_{3}\right)_{3}\right.$. $9 \mathrm{H}_{2} \mathrm{O}, \geq 99.99 \%$ trace metals basis], and titanium oxyacetylacetonate $\left(\mathrm{TiO}\left[\mathrm{CH}_{3} \mathrm{COCH}=\mathrm{C}(\mathrm{O}-) \mathrm{CH}_{3}\right]_{2}\right.$, Aldrich, $90 \%)$ were used as starting materials.

Undoped and doped nano-sized $\mathrm{ZnGa}_{2} \mathrm{O}_{4}$ spinel compositions were synthesized by the combustion reaction of oxidizing and reducing agents. ${ }^{31)}$ For a typical synthesis of nano-sized undoped $\mathrm{ZnGa}_{2} \mathrm{O}_{4}$, the stoichiometric amounts of $\mathrm{Zn}\left(\mathrm{NO}_{3}\right)_{2} \cdot 6 \mathrm{H}_{2} \mathrm{O}(1 \mathrm{mmol})$ and $\mathrm{Ga}\left(\mathrm{NO}_{3}\right)_{3}$. $x \mathrm{H}_{2} \mathrm{O}(2 \mathrm{mmol})$ were mixed in distilled water in an alumina crucible, and gently stirred at room temperature for homogeneity until completely dissolved. An appropriate amount of urea $(6.6 \mathrm{mmol})$ was added to the solution at room temperature.

The synthetic reaction was initiated by heating the solution to $150^{\circ} \mathrm{C}$ using a hot plate. This increased the viscosity of the solution with no precipitation, and $\mathrm{NO}_{x}$ gas evolved from nitrate decomposition. The mixture was held at $150^{\circ} \mathrm{C}$ to evaporate excess water until no gas was released. This formed a white gel-like precursor, which was then calcined in a pre-heated box furnace in the ambient atmosphere at various temperatures. The synthesized powders were ground in an agate mortar for powder characterization. The $\mathrm{Cr}^{3+}$-doped and $\mathrm{Ti}^{3+}$-doped $\mathrm{ZnGa}_{2} \mathrm{O}_{4}$ nanophosphors were synthesized by the same procedure as the undoped sample. Doping for the highest luminescence was achieved by adding 0.5 at. $\% \mathrm{Cr}\left(\mathrm{NO}_{3}\right)_{3} \cdot 9 \mathrm{H}_{2} \mathrm{O}$ or $\mathrm{TiO}\left[\mathrm{CH}_{3} \mathrm{COCH}=\mathrm{C}\left(\mathrm{O}_{-}\right) \mathrm{CH}_{3}\right]_{2}$ to the zinc and gallium precursors.

For a comparison micronsized undoped $\mathrm{ZnGa}_{2} \mathrm{O}_{4}, \mathrm{Cr}-$ doped $\mathrm{ZnGa}_{2} \mathrm{O}_{4}$ and Ti-doped $\mathrm{ZnGa}_{2} \mathrm{O}_{4}$ was also synthesised via the solid-state reaction using $\mathrm{ZnO}$ (Sigma-Aldrich, ACS reagent), $\mathrm{Ga}_{2} \mathrm{O}_{3}$ (Sigma-Aldrich, $\geq 99.99 \%$ trace metals basis), $\mathrm{Cr}_{2} \mathrm{O}_{3}$ (Sigma-Aldrich, $99.9 \%$ trace metals basis,), and $\mathrm{TiO}_{2}$ (Sigma-Aldrich, 325 mesh, $\geq 99 \%$ trace metals basis) powder as precursors. Stoichiometric amount of precursors are mixed by ball-milling in ethanol media for $20 \mathrm{~h}$. The suspension was dried in an oven at $90^{\circ} \mathrm{C}$ for overnight. The obtained powder were calcined at $1200^{\circ} \mathrm{C}$ for $4 \mathrm{~h}$.

\subsection{Characterization}

Powder XRD analyses were used to identify the phases present and to calculate crystallite sizes. The diffractometer (D8-Advance, Bruker, Billerica, MA, USA) used monochromatized $\mathrm{Cu}-\mathrm{K} \alpha$ radiation $(\lambda=1.54148 \AA)$. The powder samples were also analysed by HR-TEM (3000F, JEOL). The excitation and emission spectra were recorded at room temperature using a spectrofluorometer (QuantaMaster 300, PTI) equipped with a wavelength filter in the range of $400-800 \mathrm{~nm}$. A CNO analyser (EC200AC, LECO) was used to measure the oxygen content. To determine the oxidation states of the $\mathrm{Cr}$ and $\mathrm{Ti}$ dopant ions, XPS was conducted, and all measurements were calibrated to the binding energy of the $\mathrm{C} 1 \mathrm{~s}$ peak at $284.6 \mathrm{eV}$.

\section{Results and discussion}

\subsection{Characteristics of $\mathrm{ZnGa}_{2} \mathrm{O}_{4}$}

Figure 1 shows the XRD patterns of the undoped$\mathrm{ZnGa}_{2} \mathrm{O}_{4}$ nanoparticles synthesized by combustion and calcined at various temperatures up to $1000^{\circ} \mathrm{C}$ for $1 \mathrm{~h}$. Despite the significant peak broadening due to the nanosized particles, all the diffraction peaks [Figs. 1(b)-1(e)],

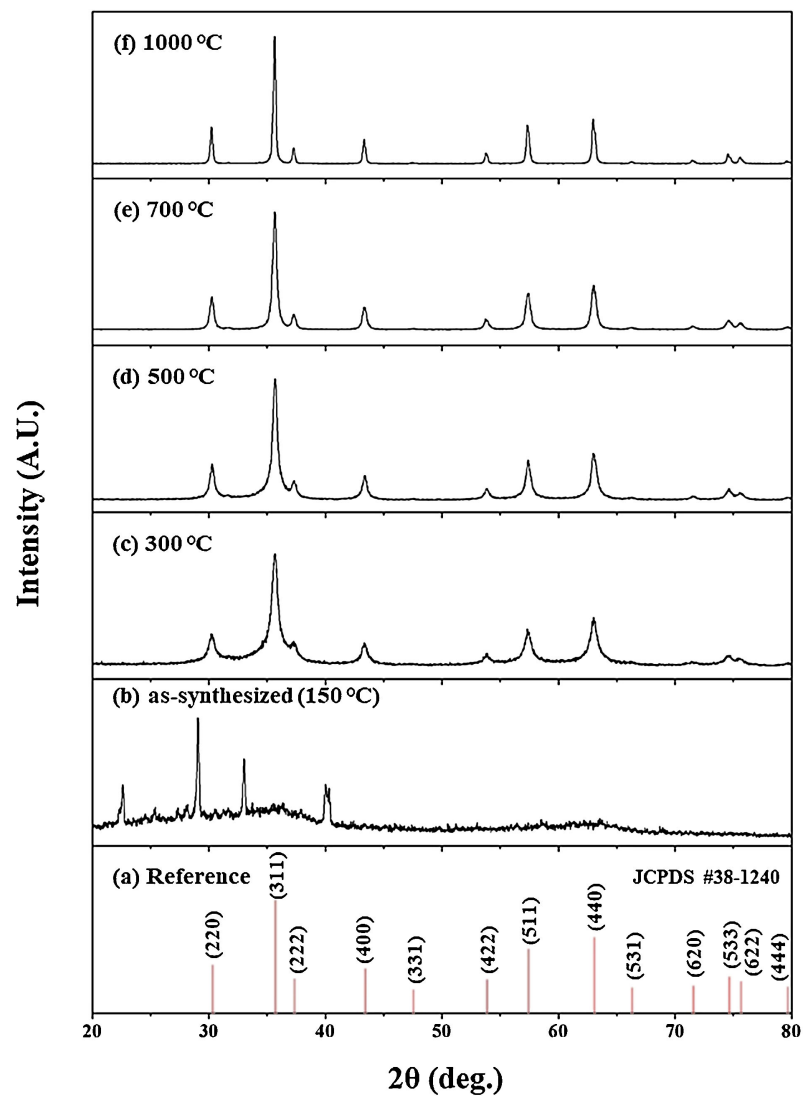

Fig. 1. XRD patterns of spinel $\mathrm{ZnGa}_{2} \mathrm{O}_{4}$ (a) JCPDS 38-1240 standard reference, (b) as-synthesized $\mathrm{ZnGa}_{2} \mathrm{O}_{4}$, and the samples calcined for $1 \mathrm{~h}$ at (c) 300 , (d) 500 , (e) $700^{\circ} \mathrm{C}$ and (f) $1000^{\circ} \mathrm{C}$. 
except for that of the as-prepared sample processed at $150^{\circ} \mathrm{C}$ [Fig. 1(a)], were well matched with the reference peaks for cubic spinel $\mathrm{ZnGa}_{2} \mathrm{O}_{4}$ (JCPDS \#38-1240). This confirms the formation of single-phase $\mathrm{ZnGa}_{2} \mathrm{O}_{4}$ without any secondary phases.

XRD patterns of undoped $\mathrm{ZnGa}_{2} \mathrm{O}_{4}, 0.5$ at.\% Cr-doped $\mathrm{ZnGa}_{2} \mathrm{O}_{4}$, and 0.5 at. $\%$ Ti-doped $\mathrm{ZnGa}_{2} \mathrm{O}_{4}$ are shown in Fig. 2. All samples were synthesized at $500^{\circ} \mathrm{C}$ for $1 \mathrm{~h}$. It is interesting to note that the addition of Ti to $\mathrm{ZnGa}_{2} \mathrm{O}_{4}$ slows the crystallization of the powder while high crystallinity of the phosphors is obtained from undoped and $\mathrm{Cr}$ -

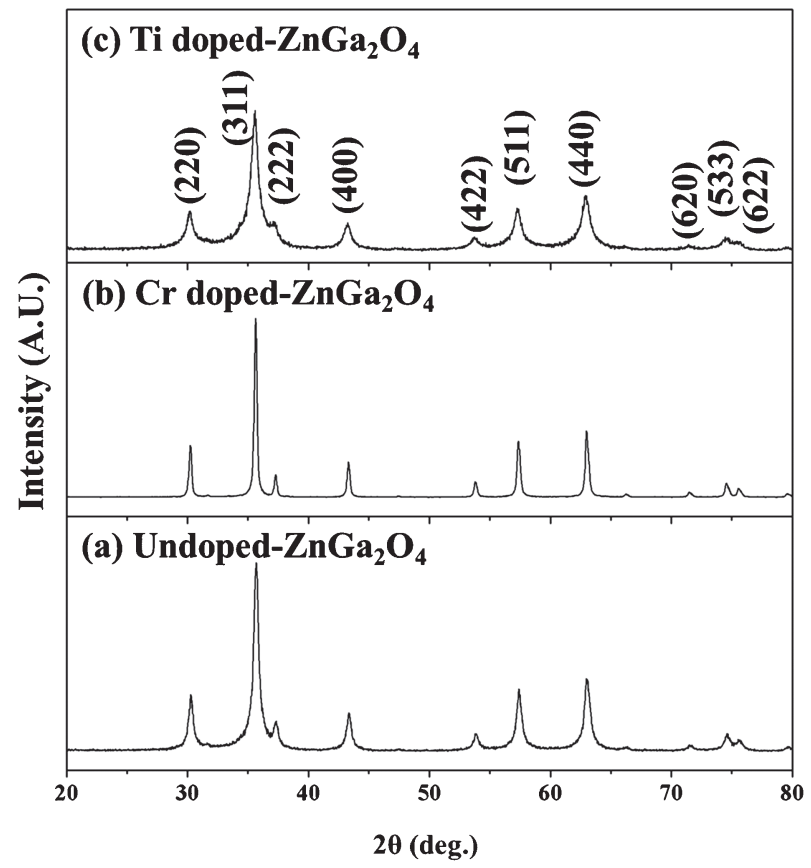

Fig. 2. XRD patterns of $\mathrm{ZnGa}_{2} \mathrm{O}_{4}$. (a) undoped $\mathrm{ZnGa}_{2} \mathrm{O}_{4}$, (b) $\mathrm{Cr}$-doped $\mathrm{ZnGa}_{2} \mathrm{O}_{4}$, (c) Ti-doped $\mathrm{ZnGa}_{2} \mathrm{O}_{4}$ synthesized at $500^{\circ} \mathrm{C}$ for $1 \mathrm{~h}$. doped $\mathrm{ZnGa}_{2} \mathrm{O}_{4}$. The average crystallite sizes of undoped $\mathrm{ZnGa}_{2} \mathrm{O}_{4}, 0.5$ at. $\%$ Cr-doped $\mathrm{ZnGa}_{2} \mathrm{O}_{4}$, and 0.5 at. $\%$ Tidoped $\mathrm{ZnGa}_{2} \mathrm{O}_{4}$ estimated from the XRD patterns by using Scherrer's equation are 27,32 , and $25 \mathrm{~nm}$, respectively. It should be attributed to the size of ions replacing Ga site as will be discussed later. It is reported that the sizes of $\mathrm{Ti}^{3+}$, $\mathrm{Ti}^{4+}$ and $\mathrm{Cr}^{3+}$ are $0.081,0.0745$ and $0.0615 \mathrm{~nm}$, respectively, whereas that of $\mathrm{Ga}^{3+}$ is $0.062 \mathrm{~nm}$. The large size Ti ions retard the crystallization process effectively in the nano structure.

The average crystallite sizes of undoped $\mathrm{ZnGa}_{2} \mathrm{O}_{4}$ heattreated at different temperatures is shown in Fig. 3. The sample heat-treated at $300^{\circ} \mathrm{C}$ for $1 \mathrm{~h}$ showed the smallest calculated average crystallite size of $5.3 \mathrm{~nm}$, whereas $1000^{\circ} \mathrm{C}$ heat treatment for $1 \mathrm{~h}$ produced $85 \mathrm{~nm}$ in size (Fig. 3, open circles). Lattice parameters were also estimated by using Bragg's law (Fig. 3, closed squares). Increasing the calcination temperature generally increased the parameter from 8.33 to $8.36 \AA$, which matches the ICSD value of $8.362 \AA{ }^{32), 33)}$ indicating improved crystallinity of the powder at $1000^{\circ} \mathrm{C}$.

Figure 4 shows HR-TEM images of undoped $\mathrm{ZnGa}_{2} \mathrm{O}_{4}$ [Figs. 4(a)-4(d)] synthesized at $300^{\circ} \mathrm{C}$ for $1 \mathrm{~h}$ along with that of bulk $\mathrm{ZnGa}_{2} \mathrm{O}_{4}$ [Figs. 4(e) and 4(f)]. The particles in Fig. 4(c) have an average size of $\sim 5.0 \mathrm{~nm}$, which is consistent with the size obtained from the XRD result. From the selected-area electron diffraction (SAED) patterns in Fig. 4(d), the (111), (311), and (220) spots of $\mathrm{ZnGa}_{2} \mathrm{O}_{4}$ were identified with the [112] zone axis. The lattice parameter was calculated to be in the range of $0.8334-0.8364 \mathrm{~nm}$ using (311) d-spacings of 0.2513-0.2522 nm. TEM image of bulk $\mathrm{ZnGa}_{2} \mathrm{O}_{4}$ in Fig. 4(e), which was prepared by a conventional solid-state reaction at $1200^{\circ} \mathrm{C}$ for $4 \mathrm{~h}$, shows particles much larger than the combustion synthesized $\mathrm{ZnGa}_{2} \mathrm{O}_{4}$. The calculated lattice parameter for solid-state reacted $\mathrm{ZnGa}_{2} \mathrm{O}_{4}$ using (311) d-spacing of $0.2517 \mathrm{~nm}$ from

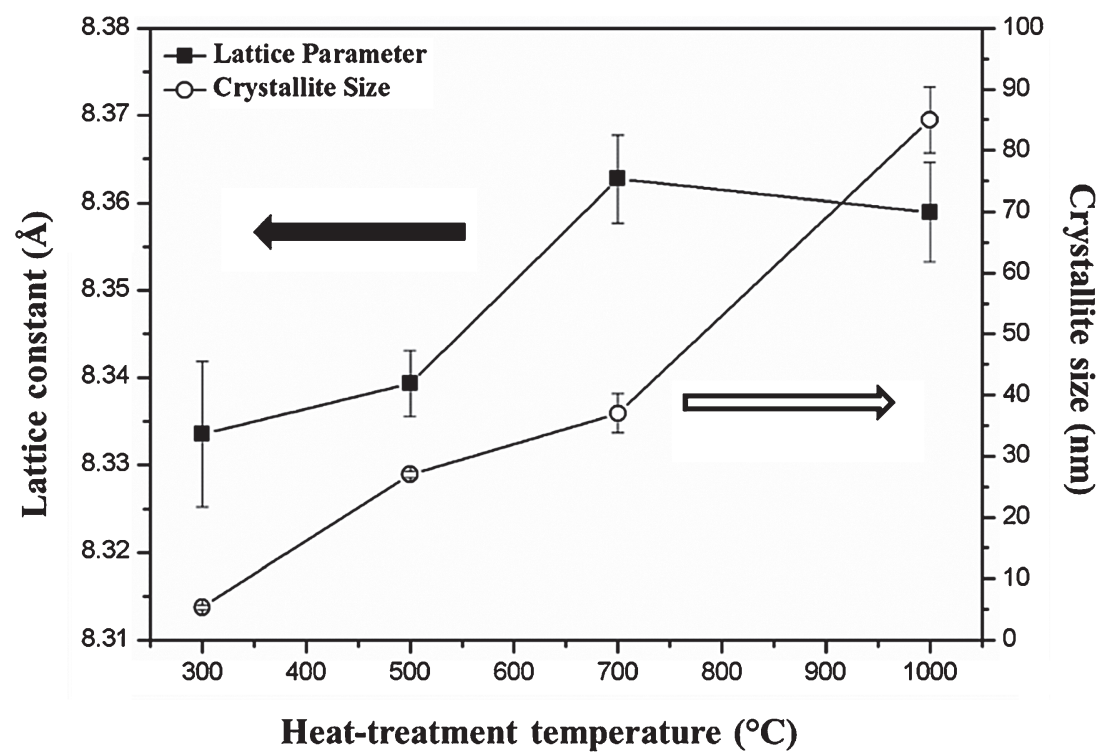

Fig. 3. Calculated lattice constants and crystallite sizes of various $\mathrm{ZnGa}_{2} \mathrm{O}_{4}$ calcined between 300 and $1000^{\circ} \mathrm{C}$ for $1 \mathrm{~h}$. 


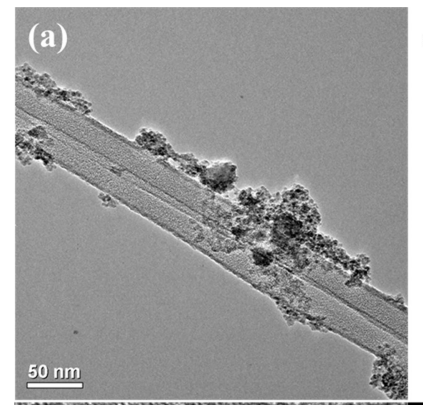

(b)

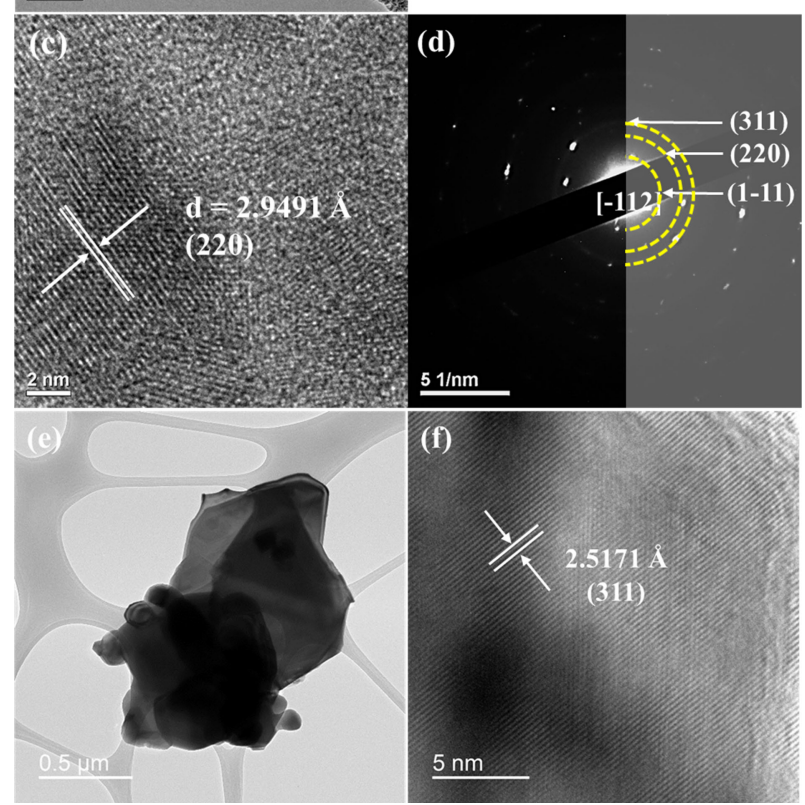

Fig. 4. (a) TEM image, (b) XRD pattern, (c) HR-TEM image, and (d) SAED pattern of undoped $\mathrm{ZnGa}_{2} \mathrm{O}_{4}$ synthesized at $300^{\circ} \mathrm{C}$ for $1 \mathrm{~h}$, (e) TEM image and (f) HR-TEM image of bulk $\mathrm{ZnGa}_{2} \mathrm{O}_{4}$ prepared by solid-state reaction at $1200^{\circ} \mathrm{C}$ for $4 \mathrm{~h}$.

its HR-TEM [Fig. 4(f)] was $0.8348 \mathrm{~nm}$, which is similar to the lattice parameter, $0.83349 \mathrm{~nm}$, in JCPDS 38-1240.

\subsection{Luminescence of $\mathrm{ZnGa}_{2} \mathrm{O}_{4}$ phosphors}

Figure 5 shows the PLE spectra of undoped and doped samples prepared at $500^{\circ} \mathrm{C}$ for $1 \mathrm{~h}$ (solid-lines) and micron-sized sample prepared by solid-state reaction (dashed-lines). All undoped $\mathrm{ZnGa}_{2} \mathrm{O}_{4}$ generally exhibits the characteristic blue emission at $430 \mathrm{~nm}(2.88 \mathrm{eV})$ under $254 \mathrm{~nm}$ UV excitation that originates from charge transfer from $\mathrm{O}$ to $\mathrm{Ga}$ in the host material. ${ }^{20)}$ However, the spectrum in Fig. 5(a) for nano-sized $\mathrm{ZnGa}_{2} \mathrm{O}_{4}$ exhibits several peaks at $420(2.95 \mathrm{eV}), 450(2.75 \mathrm{eV}), 470(2.63 \mathrm{eV}), 480$ $(2.58 \mathrm{eV})$, and $490(2.53 \mathrm{eV}) \mathrm{nm}$, a bell-shaped spectrum. The low crystallinity of the nano $\mathrm{ZnGa}_{2} \mathrm{O}_{4}$ along with a high defect density should be responsible for the various emission peaks. Emission at $\sim 560 \mathrm{~nm}(2.21 \mathrm{eV})$ was also observed, which has previously been obtained by doping $\mathrm{ZnGa}_{2} \mathrm{O}_{4}$ with $\mathrm{Mn}^{2+}{ }^{24)}$ Synthesis by combustion with an organic-containing precursor is known to provide a large number of oxygen vacancies, resulting in emission peak at $680 \mathrm{~nm}(1.82 \mathrm{eV}) .{ }^{35)}$ Based on these facts, it can be said that it is more probable for nano-sized $\mathrm{ZnGa}_{2} \mathrm{O}_{4}$ to provide white emission than micron-sized ones.
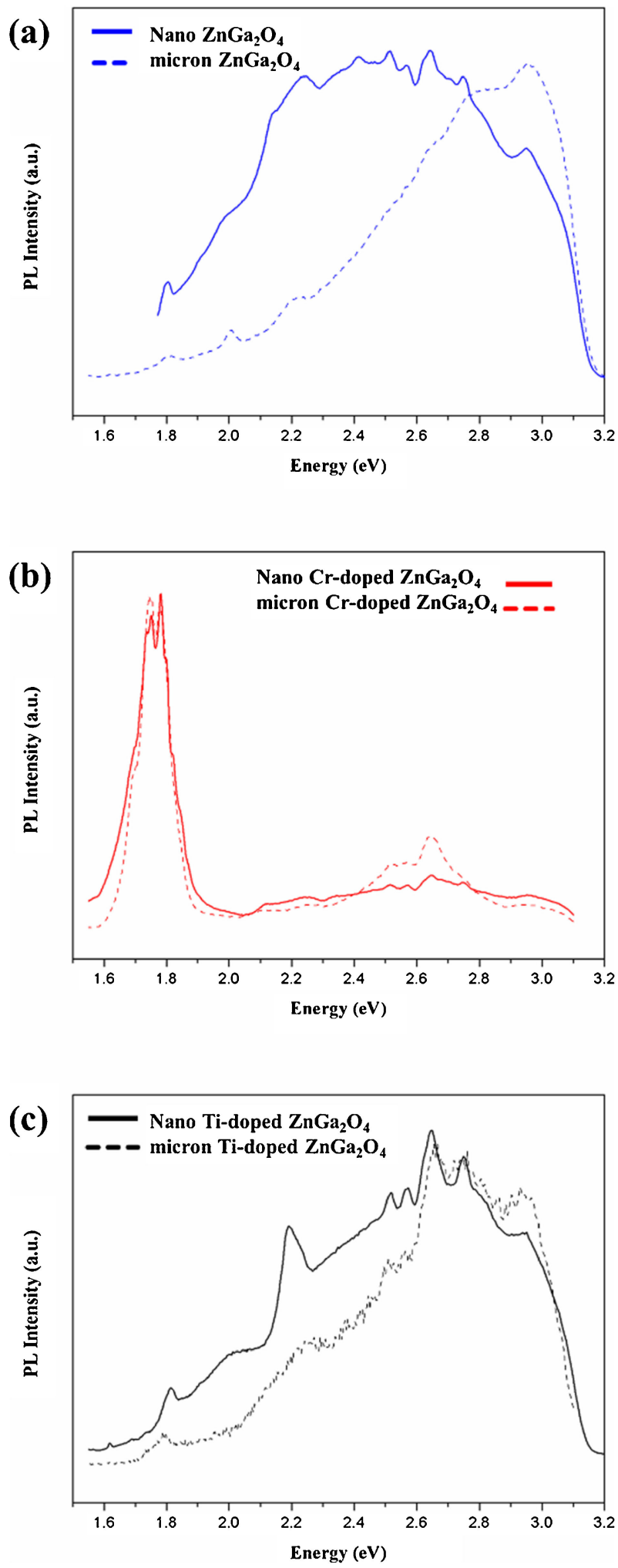

Fig. 5. PLE spectra of (a) pure micron and nano $\mathrm{ZnGa}_{2} \mathrm{O}_{4}$, (b) 0.5 at.\% Cr-doped micron and nano $\mathrm{ZnGa}_{2} \mathrm{O}_{4}$, and (c) 0.5 at.\% Ti-doped micron and nano $\mathrm{ZnGa}_{2} \mathrm{O}_{4}$.

The PLE spectrum of Cr-doped $\mathrm{ZnGa}_{2} \mathrm{O}_{4}$ (0.5 at.\%) excited at $254 \mathrm{~nm}$ [Fig. 5(b)] shows a high-intensity peak $\sim 695 \mathrm{~nm}(1.78 \mathrm{eV})$ regardless of the powder size. The $\mathrm{Cr}^{3+}$ ions are reported to substitute $\mathrm{Ga}^{3+}$ ions at octahedral 

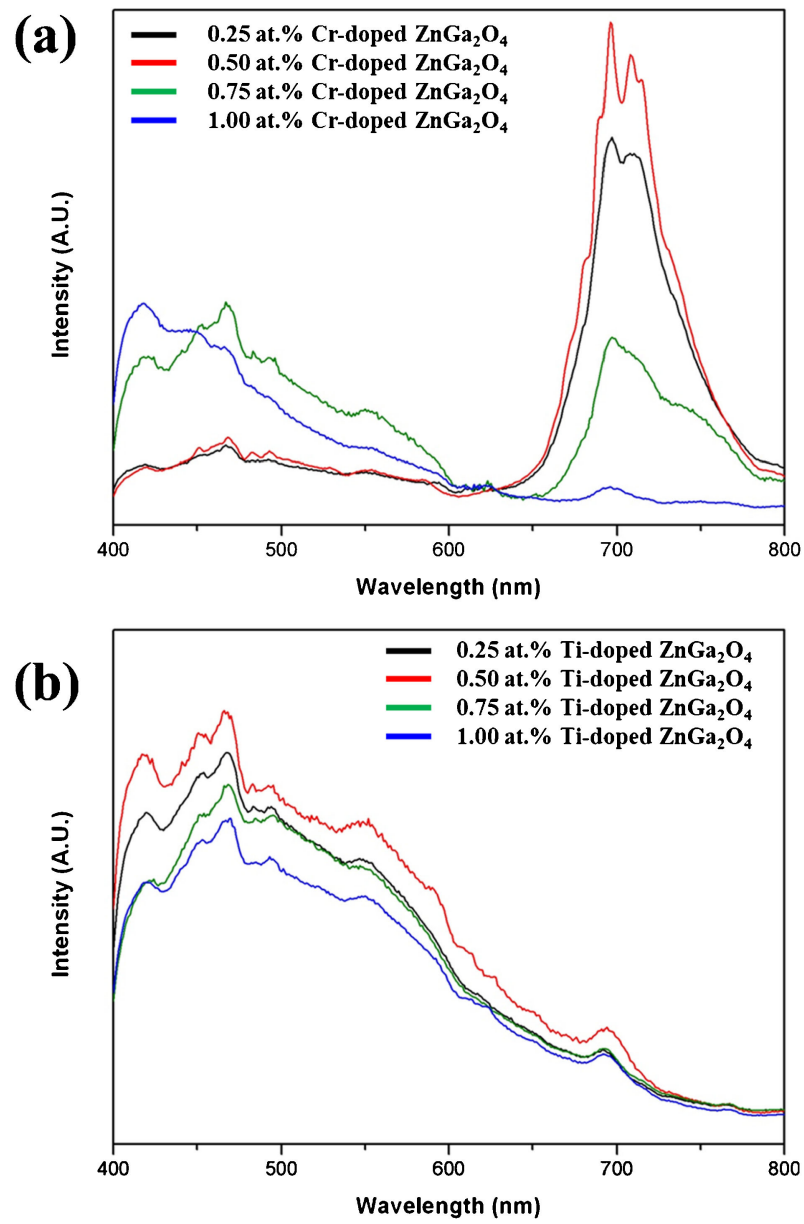

Fig. 6. PLE spectra of combusted nano $\mathrm{ZnGa}_{2} \mathrm{O}_{4}$ doped with varying concentration levels of (a) $\mathrm{Cr}$ and (b) $\mathrm{Ti}$ excited under $254 \mathrm{~nm}$ excitation. The amounts of dopants are between 0.25 and 1.00 at.\% for $\mathrm{Cr}$ and Ti-doped $\mathrm{ZnGa}_{2} \mathrm{O}_{4}$.

sites to minimize charge and size variation. ${ }^{36)}$ Their oxidation state is suggested to be +3 . Excitation at $254 \mathrm{~nm}$ causes the charge transfer in $\mathrm{CrO}^{6+}$; the ${ }^{4} \mathrm{~A}_{2}{ }^{4} \mathrm{~T}_{1}$ transition of $\mathrm{Cr}^{3+}$ and the emission band around $695 \mathrm{~nm}$ are attributed to the ${ }^{2} \mathrm{E}-{ }^{4} \mathrm{~A}_{2}$ transition of $\mathrm{Cr}^{3+}$ in the octahedral sites. ${ }^{6), 15), 36)}$ Furthermore, the intrinsic blue emission of pure $\mathrm{ZnGa}_{2} \mathrm{O}_{4}$ host material was largely suppressed, indicating that the energy to the $\mathrm{Cr}^{3+}$ ions was highly efficient, resulting in red emission only. On contrary, Cr-doped $\mathrm{ZnGa}_{2} \mathrm{O}_{4}$ synthesized by solid-state reaction exhibited the intrinsic blue emission peaks in addition to red emission, reducing the efficiency of red colour. The PLE spectrum of $0.5 \%$ Ti-doped $\mathrm{ZnGa}_{2} \mathrm{O}_{4}$ shows bluish-white emission, Fig. 5(c), with a broad peak that consisted of almost all three primary colours: blue, green, and red. Similar to undoped samples, Ti-doped nano $\mathrm{ZnGa}_{2} \mathrm{O}_{4}$ tends to have various emission wavelengths even if red one is relatively weak, resulting in a bluish-white emission.

Optimum concentrations were sought for both dopants at contents ranging between 0.25 and 1.00 at.\% and the results are shown in Fig. 6. Excitation was at $254 \mathrm{~nm}$ with equal amounts of powder. In both cases, the PLE intensity increased with dopant concentration up to 0.5 at. $\%$, beyond which it decreased. The red emission of Cr-doped $\mathrm{ZnGa}_{2} \mathrm{O}_{4}$ decreased at concentrations greater than 0.5 at. \%, and further addition of $\mathrm{Cr}$ ions led to the intrinsic blue emission of $\mathrm{ZnGa}_{2} \mathrm{O}_{4}$ [Fig. 6(a)]. There was no further suppression of the blue emission. In contrast, the Ti-doped $\mathrm{ZnGa}_{2} \mathrm{O}_{4}$ showed no notable PLE shift or shape change, except that increasing the dopant concentration decreased the emission intensity [Fig. 6(b)]. Doping at 0.3 to 0.5 at.\% is generally considered acceptable. ${ }^{14), 37), 38)}$ Based on the results discussed to this point it can be concluded that $\mathrm{ZnGa}_{2} \mathrm{O}_{4}$ has potential as a host material to provide white emission, at least, by mixing singly-doped $\mathrm{ZnGa}_{2} \mathrm{O}_{4}$ in nano size.

\subsection{Oxidation state of the dopants}

Figure 7 shows the wide-scan XPS spectrum for undoped $\mathrm{ZnGa}_{2} \mathrm{O}_{4}$ and fine scans for both doped samples. The spectrum of undoped $\mathrm{ZnGa}_{2} \mathrm{O}_{4}$ in Fig. 7(a) indicates the presence of all three constituent elements. The spectra for the doped samples also show the presence of all the constituent elements without any observable contamination other than a very small peak for adsorbed carbon. The fine XPS spectrum in Fig. 7(b) shows the Cr 2p $\mathrm{p}_{3 / 2}$ (574 $\mathrm{eV})$ and $\mathrm{Cr} 2 \mathrm{p}_{1 / 2}(585 \mathrm{eV})$ peaks with an $11 \mathrm{eV}$ difference between them. This binding energy corresponds to $\mathrm{Cr}^{3+}$ in a trivalent oxidation state. All the values and the gaps between them in the fine XPS of $\mathrm{Ga}, \mathrm{Zn}$, and $\mathrm{Cr}$ agreed with the reference values, ${ }^{39)}$ confirming the existence of a $\mathrm{Cr}^{3+}$ trivalent oxidation state.

XPS spectra of Ti-doped $\mathrm{ZnGa}_{2} \mathrm{O}_{4}$ synthesized at 500 and $1000^{\circ} \mathrm{C}$ [Figs. $7(\mathrm{c})$ and $7(\mathrm{~d})$ ] were taken to verify the valence state of the titanium ions in the spinel structure. Titanium ions can have various valence states that affect their photoluminescence along with the doping sites. The wide spectra reveal the presence of all four elements (not shown), and the detailed scan in Fig. 7(c) shows peaks at 456.70 and $458.15 \mathrm{eV}$ which correspond to reported values for the $\mathrm{Ti}^{3+} 2 \mathrm{p}_{3 / 2}$ and $\mathrm{Ti}^{4+} 2 \mathrm{p}_{1 / 2}$ states, respectively. ${ }^{39), 40)}$ It confirms the co-existence of $\mathrm{Ti}^{3+}$ and $\mathrm{Ti}^{4+}$ in the spinel structure. We have previously reported similar results for Ti-doped $\mathrm{MgAl}_{2} \mathrm{O}_{4}$ spinel. ${ }^{41)}$ High-intensity $\mathrm{Ti}^{3+}$ signals are evident for samples heat-treated at both 500 and $1000^{\circ} \mathrm{C}$, and are larger at $1000^{\circ} \mathrm{C}$, indicating that the trivalent oxidation state is more favorable at higher temperatures.

\section{Conclusions}

Nano-sized undoped, $\mathrm{Cr}^{3+}$-doped, and $\mathrm{Ti}^{3+}$-doped $\mathrm{ZnGa}_{2} \mathrm{O}_{4}$ spinel particles were synthesized by a combustion method based on the nitrate-urea redox reaction. XRD and HR-TEM results identified $5-10 \mathrm{~nm}$ nanoparticles with a spinel structure. The blue PLE of the undoped $\mathrm{ZnGa}_{2} \mathrm{O}_{4}$ at room temperature originated from charge transfer between $\mathrm{Ga}$ and $\mathrm{O}$ was suppressed and the spectra became broadened when the phosphor particle size decreased. It is attributed to the presence of various defects and low crytallinity of nano phosphors. Ti-doped $\mathrm{ZnGa}_{2} \mathrm{O}_{4}$ exhibited a bluish-white emission consisting of blue, 

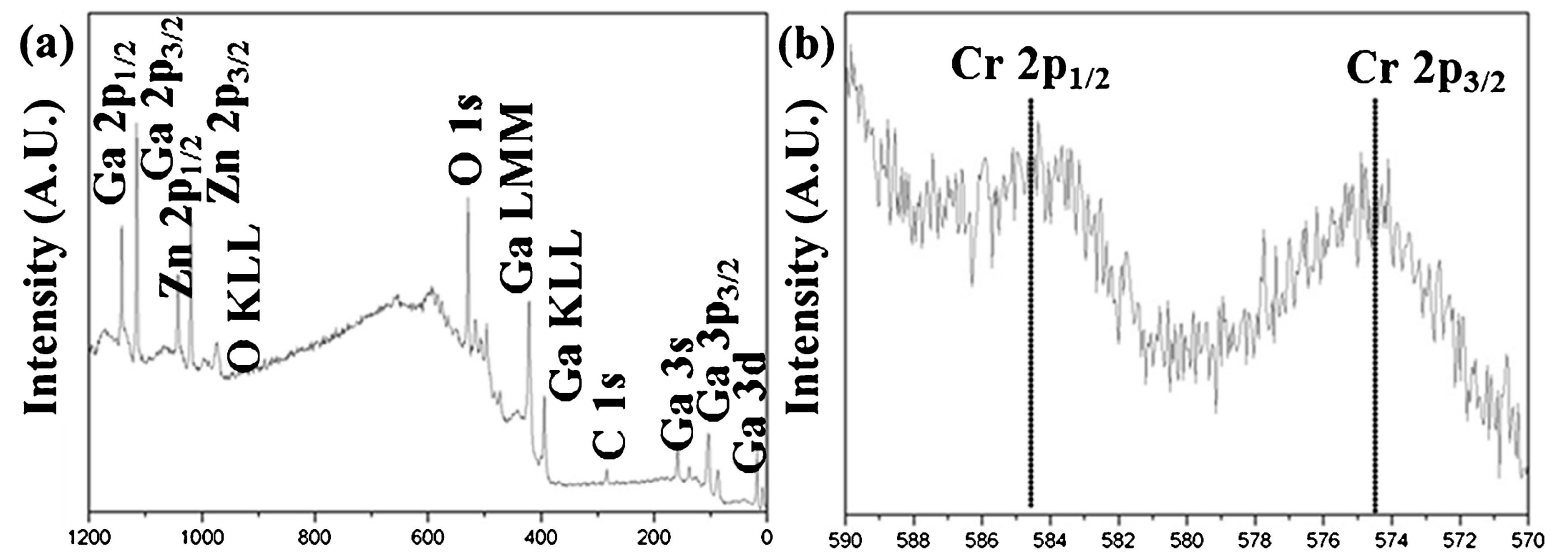

Binding energy (eV)
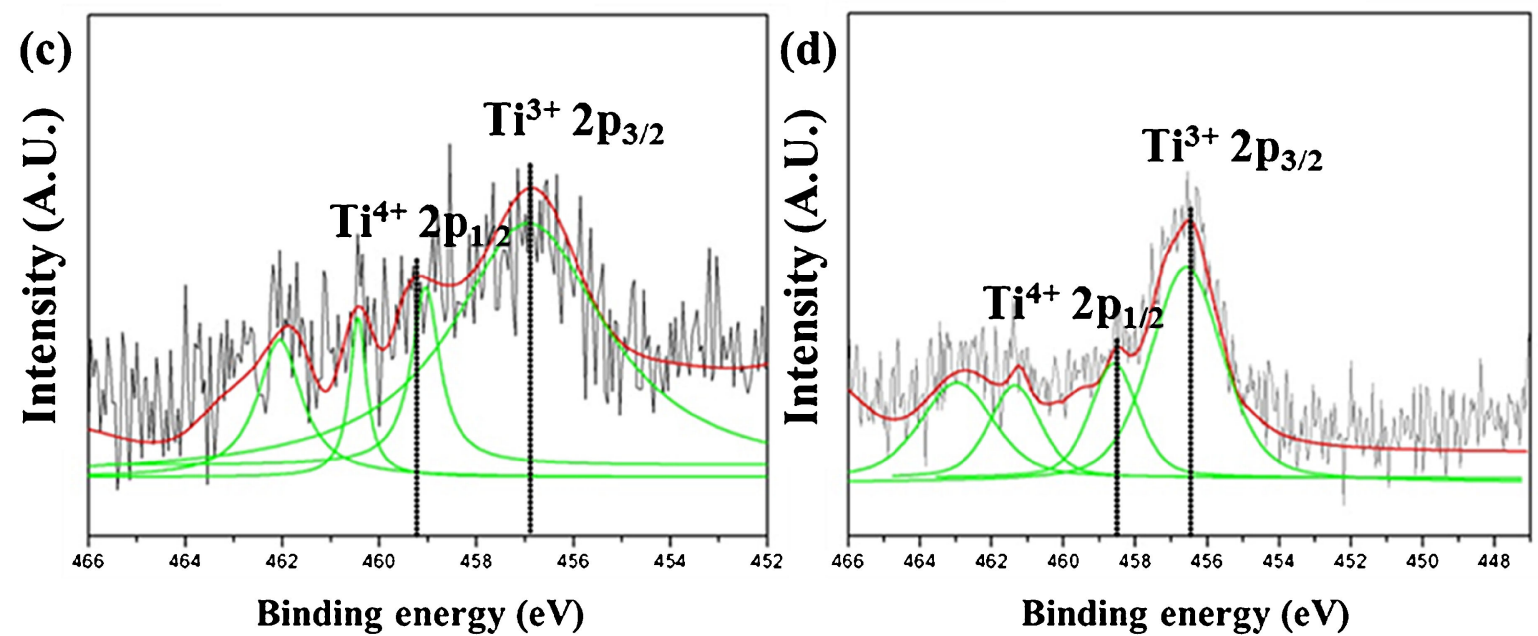

Fig. 7. (a) Wide-scan XPS spectrum for pure $\mathrm{ZnGa}_{2} \mathrm{O}_{4}$. Narrow-scan XPS spectra for (b) $\mathrm{Cr}^{3+}$ ions and (c) $\mathrm{Ti}^{3+}$ and $\mathrm{Ti}^{4+}$ ions in separately doped $\mathrm{ZnGa}_{2} \mathrm{O}_{4}$ synthesized at $500^{\circ} \mathrm{C}$ for $1 \mathrm{~h}$ and (d) $\mathrm{Ti}^{3+}$ and $\mathrm{Ti}^{4+}$ ions in doped $\mathrm{ZnGa}_{2} \mathrm{O}_{4}$ synthesized at $1000^{\circ} \mathrm{C}$ for $1 \mathrm{~h}$.

green, and red emissions under excitation at $254 \mathrm{~nm}$ while intensive red emission at $695 \mathrm{~nm}(1.78 \mathrm{eV})$ was observed from $\mathrm{Cr}^{3+}$-doped $\mathrm{ZnGa}_{2} \mathrm{O}_{4}$. The XPS results indicate that the $\mathrm{Ti}$ dopant is present in both the trivalent $\left(\mathrm{Ti}^{3+}\right)$ and tetravalent $\left(\mathrm{Ti}^{4+}\right)$ oxidation states, with the trivalent state more favourable within $\mathrm{ZnGa}_{2} \mathrm{O}_{4}$ spinel structure at high temperature. Nano $\mathrm{ZnGa}_{2} \mathrm{O}_{4}$ exhibits potential as a host material to provide white emission.

Acknowledgment This work was supported by the IT R\&D program of MKE/KEIT [10047010] Korea. We acknowledge the Research Institute of Advanced Materials, Seoul National University for the use of facilities.

\section{References}

1) A. R. Phani, S. Santucci, S. Di Nardo, L. Lozzi, M. Passacantando, P. Picozzi and C. Cantalini, J. Mater. Sci., 33, 3969-3973 (1998).

2) Q. Shi, J. Y. Zhang, C. Cai, L. Cong and T. M. Wang, Mater. Sci. Eng. B-Adv., 149, 82-86 (2008).

3) International Tables for Crystallography, in: 1st online ed. Chester: International Union of Crystallography (2006).
4) K. H. Hsu, M. R. Yang and K. S. Chen, J. Mater. Sci.Mater. El., 9, 283-288 (1998).

5) L. Zou, X. Xiang, M. Wei, F. Li and D. G. Evans, Inorg. Chem., 47, 1361-1369 (2008).

6) A. Bessiere, S. Jacquart, K. Priolkar, A. Lecointre, B. Viana and D. Gourier, Opt. Express, 19, 10131-10137 (2011).

7) Y. X. Zhuang, J. Ueda, S. Tanabe and P. Dorenbos, J. Mater. Chem. C, 2, 5502-5509 (2014).

8) S. K. Sharma, D. Gourier, B. Viana, T. Maldiney, E. Teston, D. Scherman and C. Richard, Opt. Mater., 36, 1901-1906 (2014).

9) K. Ikarashi, J. Sato, H. Kobayashi, N. Saito, H. Nishiyama and Y. Inoue, J. Phys. Chem. B, 106, 9048-9053 (2002).

10) R. D. Zhang, A. Villanueva, H. Alamdari and S. Kallaguine, Catal. Commun., 9, 111-116 (2008).

11) X. Chen, H. Xue, Z. H. Li, L. Wu, X. X. Wang and X. Z. Fu, J. Phys. Chem. C, 112, 20393-20397 (2008).

12) D. R. Li, Y. H. Wang, K. Xu, L. Li, Z. F. Hu and H. Zhao, Opt. Mater., 42, 313-318 (2015).

13) C. F. Yu and P. Lin, J. Appl. Phys., 79, 7191-7197 (1996).

14) Y. Zhang, Z. J. Wu, D. L. Geng, X. J. Kang, M. M. Shang, X. J. Li, H. Z. Lian, Z. Y. Cheng and J. Lin, $A d v$. 
Funct. Mater, 24, 6581-6593 (2014).

15) P. D. Rack, J. J. Peterson, M. D. Potter and W. Park, J. Mater. Res., 16, 1429-1433 (2001).

16) B. B. Srivastava, A. X. Kuang and Y. B. Mao, Chem. Commun., 51, 7372-7375 (2015).

17) N. Basavaraju, K. R. Priolkar, D. Gourier, A. Bessiere and B. Viana, Phys. Chem. Chem. Phys., 17, 1099310999 (2015).

18) N. Basavaraju, K. R. Priolkar, D. Gourier, S. K. Sharma, A. Bessiere and B. Viana, Phys. Chem. Chem. Phys., 17, 1790-1799 (2015).

19) J. H. Jeong, B. K. Moon, H. J. Seo, J. S. Bae, S. S. Yi, I. W. Kim and H. L. Park, Appl. Phys. Lett., 83, 13461348 (2003).

20) H. J. Byun, J. U. Kim and H. Yang, Nanotechnology, 20, 495602 (2009).

21) Y. F. Zhang, L. Li, X. S. Zhang and Q. Xi, J. Rare Earth., 26, 446-449 (2008).

22) W. R. Liu, C. H. Huang, C. W. Yeh, J. C. Tsai, Y. C. Chiu, Y. T. Yeh and R. S. Liu, Inorg. Chem., 51, 96369641 (2012).

23) Y. X. Zhuang, J. Ueda and S. Tanabe, Opt. Mater. Express, 2, 1378-1383 (2012).

24) M. J. Hampden-Smith, T. T. Kodas, J. Caruso, D. J. Skamser and Q. H. Powell, Oxygen-containing phosphor powders, methods for making phosphor powders and devices incorporating same, in, Google Patents (2001).

25) H. S. Roh, Y. C. Kang, S. B. Park and H. D. Park, Jpn. J. Appl. Phys., 1, 4559-4562 (2002).

26) J. Dhanaraj, R. Jagannathan, T. R. N. Kutty and C. H. Lu, J. Phys. Chem. B, 105, 11098-11105 (2001).

27) T. Kim and S. Kang, Mater. Res. Bull., 40, 1945-1954 (2005).

28) C. X. Qin, M. B. Gu, Y. L. Huang, L. X. Dai, G. Q.
Chen, L. Shi, X. B. Qiao and H. J. Seo, J. Nanosci. Nanotechnol., 11, 9570-9575 (2011).

29) J. Y. Chong, Y. L. Zhang, B. K. Wagner and Z. T. Kang, J. Alloy. Compd., 581, 484-487 (2013).

30) J. K. Han, J. I. Choi, A. Piquette, M. Hannah, M. Anc, M. Galvez, J. B. Talbot and J. McKittrick, Ecs J. Solid State Sc., 2, R3138-R3147 (2013).

31) S. R. Jain, K. C. Adiga and V. R. P. Verneker, Combust. Flame, 40, 71-79 (1981).

32) J. S. Kim, H. L. Park, C. M. Chon, H. S. Moon and T. W. Kim, Solid State Commun., 129, 163-167 (2004).

33) S. H. Wu and H. C. Cheng, J. Electrochem. Soc., 151, H159-H163 (2004).

34) M. Takesada, T. Isobe, H. Takahashi and S. Itoh, J. Electrochem. Soc., 154, J136-J140 (2007).

35) J. S. Kim, H. I. Kang, W. N. Kim, J. I. Kim, J. C. Choi, H. L. Park, G. C. Kim, T. W. Kim, Y. H. Hwang, S. I. Mho, M. C. Jung and M. Han, Appl. Phys. Lett., 82, 2029-2031 (2003).

36) J. S. Kim, J. S. Kim and H. L. Park, Solid State Commun., 131, 735-738 (2004).

37) Z. J. Li, Y. W. Zhang, X. Wu, X. Q. Wu, R. Maudgal, H. W. Zhang and G. Han, Adv. Sci., 2, 201500001 (2015).

38) S. K. Sharma, A. Bessiere, N. Basavaraju, K. R. Priolkar, L. Binet, B. Viana and D. Gourier, J. Lumin., 155, 251-256 (2014).

39) S. Hashimoto and A. Tanaka, Surf. Interface Anal., 34, 262-265 (2002).

40) K. Y. Yang, K. Z. Fung and M. C. Wang, J. Appl. Phys., 100, 056102 (2006).

41) J. H. Lim, B. N. Kim, Y. Kim, S. Kang, R. J. Xie, I. S. Chong, K. Morita, H. Yoshida and K. Hiraga, Appl. Phys. Lett., 102, 031104 (2013). 